\title{
Vorwort zur 8. Auflage
}

Die Welt der Banken ist seit der Jahrtausendwende von Veränderungen grundlegenden Ausmaßes geprägt. Betroffen durch die fortschreitende Globalisierung und neue Formen der wertorientierten Führung waren im Bereich der Universalbanken insbesondere die großen Kreditbanken. Aber auch für die Sparkassen und die Genossenschaftsbanken stellten sich erhebliche Herausforderungen infolge neuer regulatorischer Vorschriften. Ähnliches gilt für die Spezialbanken, deren Geschäftsgebiete gleichermaßen weitgehenden Veränderungen ausgesetzt waren. Als neuer Banktypus traten die „Bad Banks“ in Erscheinung. Dazu kamen gravierende Marktveränderungen durch die Einführung der einheitlichen europäischen Währung in Form des Euro und durch die Vorgabe neuer Regularien im Bereich des Kreditgeschäfts durch den neuen Eigenkapitalstandard „Basel II" und seit Ende 2010 durch die Vorbereitungen auf den verbesserten Standard „Basel III“.

Für eine epochale Zäsur sorgte jedoch die globale Finanzmarktkrise, die Mitte 2007 als internationale Bankenkrise ihren Anfang nahm und den rechtlichen Rahmen des deutschen und internationalen Bankwesens sowie die Struktur der Bankorganisation und die Geschäftsprozesse der Banken in bisher nicht gekannter Weise fundamental veränderte. Diese Entwicklungen machten es erforderlich, die Inhalte der 7. Auflage der Bankbetriebswirtschaftslehre in erheblicher Weise zu verändern und in großen Teilen unter Beibehaltung der bewährten Struktur dieses Lehrbuches neu zu bearbeiten. In diesem Zusammenhang ist insbesondere auf den Abschnitt über die Bankenaufsicht zu verweisen. Dieses Kapitel ist völlig neu gefasst und von exzellenten Kennern der Materie, dem vormaligen Präsidenten der Hauptverwaltung München der Deutschen Bundesbank (bis 2009), Herrn Prof. Wolfgang Simler, zusammen mit Frau Christine Riel und Mitarbeitern der Bankenaufsicht der HV München bearbeitet worden. Für Veränderungen in anderen Kapiteln bedanke ich mich für die Mitarbeit von Frau Dr. Sigrid Kletzing, Universität Rostock. Für die Mithilfe bei der Erstellung von Abbildungen bedanke ich mich bei Herrn Constantin Freiherr v. Ritter zu Groenesteyn. Ebenso gilt mein Dank meiner Frau, Traudl Eilenberger, und Frau Dipl.-Kfm. (univ.) Alexandra Freifrau v. Ritter zu Groenesteyn für vielfältige Unterstützung bei Recherchen und der Abfassung des Manuskripts.

Insgesamt habe ich die 8. Auflage schließlich gegenüber der Vorauflage einem Verschlankungsprozess unterzogen, gleichwohl aber um die erforderlichen neuen Entwicklungen in Praxis und Bankbetriebslehre ergänzt. Daher kann nunmehr wiederum ein modernes und alle Bereiche der Bankwirtschaft umfassendes Lehr- und Handbuch vorgelegt werden.

Guido Eilenberger 